\section{EMBRYAIDDLE Aeronautical University}

SCHOLARLY COMMONS

\section{International Journal of Aviation,} Aeronautics, and Aerospace

3-31-2018

\title{
Experimental investigation of a new spiral wingtip
}

\author{
Naseeb Ahmed Siddiqui \\ International Islamic University - Malaysia, siddiquinaseeb@gmail.com \\ Mohamed Aldeeb \\ International Islamic University Malaysia, m.aldheeb@gmail.com \\ Waqar Asrar \\ International Islamic University - Malaysia, waqar@iium.edu.my \\ Erwin Sulaeman \\ International Islamic University Malaysia, esulaeman@iium.edu.my
}

Follow this and additional works at: https://commons.erau.edu/ijaaa

Part of the Aerodynamics and Fluid Mechanics Commons, Aeronautical Vehicles Commons, Applied Mechanics Commons, Cosmology, Relativity, and Gravity Commons, Space Vehicles Commons, and the The Sun and the Solar System Commons

\section{Scholarly Commons Citation}

Siddiqui, N. A., Aldeeb, M., Asrar, W., \& Sulaeman, E. (2018). Experimental investigation of a new spiral wingtip. International Journal of Aviation, Aeronautics, and Aerospace, 5(2). https://doi.org/10.15394/ ijaaa.2018.1213

This Article is brought to you for free and open access by the Journals at Scholarly Commons. It has been accepted for inclusion in International Journal of Aviation, Aeronautics, and Aerospace by an authorized administrator of Scholarly Commons. For more information, please contact commons@erau.edu. 


\section{Nomenclature}

$\mathrm{C}_{\mathrm{L}}$

$\mathrm{C}_{\mathrm{D}}$

$\mathrm{C}_{\mathrm{L} \max }$

$\mathrm{C}_{\mathrm{D} \min }$

$\mathrm{L} / \mathrm{D}$ or $\mathrm{C}_{\mathrm{L}} / \mathrm{C}_{\mathrm{D}}$

$(\mathrm{L} / \mathrm{D})_{\max }$ or $\left(\mathrm{C}_{\mathrm{L}} / \mathrm{C}_{\mathrm{D}}\right)_{\max }$

AR

Cant angle

VLM

UAV

MAV
Lift coefficient

Drag coefficient

Maximum lift coefficient

Minimum drag coefficient

Lift to drag ratio

Maximum lift to drag ratio

Aspect ratio

Angle between twisted tip and wing

Vortex lattice method

Unmanned air vehicle

Micro Air vehicle 
Efficient flight performance is one of the main goals of aeronautical engineers. Wing tips improve performance by reducing the induced drag leading to decreased fuel consumption, increased range, high altitude, and reduced take-off distance (Council, 2007; Faye, Laprete, \& Winter, 2002, Siddiqui et al., 2017). However, there is still room for improvements, especially for low Reynolds number applications in UAVs and MAVs.

This research investigates a new wing tip inspired by a bird's primary feathers. Soaring birds over land have been a point of attraction for a long time especially to compare their aerodynamic behaviours with manmade gliders (Pennycuick \& Lock, 1976; Raspet, 1950). They have a unique configuration of feather tips that differs from other birds and fixed airplane wing tips. The wing tips of these birds have a slotted configuration providing a gap between primary feathers. Moreover, the tips bend and twist vertically forming almost a spiral shape. Graham (1932) first proposed that such slotted configuration has to do with induced drag; however, no experimental data was provided. Till 1950's it was assumed based on Munk's theory (Munk, 1923) that minimum induced drag could be achieved through planar wings. That assumption restricted the full attention of researchers until Newman(1958) proved that a plane lifting system is unable to reduce induced drag and proposed a non-planar wing to achieve a reduction in induced drag. Such claim triggered the attention on the study of bird feather tips finding them non-planar which can work as winglets.

Cone (1962) developed a fundamental theory for non-planar wings to find out induced drag, lift and vorticity generation. Blick et al. (1975) have studied the relationship between bird feather flexibility and speed, flexible slotted tips and wake vorticity. Fourteen different bird species have been studied by (Oehme, 1977) to determine the effect of chord depth on feathers. He found that primary feathers improve the aerodynamic behavior by reducing the induced drag. Moreover, he did not find slotted wingtips a form of leading-edge slat rather than functioning as multi-planes. Slotted wingtips may reduce induced drag in moderate range because of non-planar planform. Birds fly at low Reynolds number between $10^{4}-10^{6}$ that affect the lift and drag coefficients drastically (Hoerner, 1965; Hoerner \& Borst, 1992; Von Mises, 1959). (Withers, 1981) has done extensive studies to analyse the effect of Reynolds number over bird wings and insects. At low Reynolds numbers, bird wings have high minimum $\mathrm{Cd}$ (0.03-0.13), low $\mathrm{C}_{\mathrm{Lmax}}$ (0.8-1.2) and low $\left(\mathrm{C}_{\mathrm{L}} / \mathrm{C}_{\mathrm{D}}\right)_{\max }(3-17)$. Feathers showed low airfoil efficiency factor around (0.2-0.8) due to low Reynolds number and increased profile drag compared to a conventional airfoil that ranged from 0.9 to 0.95 (Withers, 1981). 
Tucker (1987) experimented on two real gliding birds inside a wind tunnel at a given speed. Both birds increased their drag by decreasing wing span increasing induced drag and profile drag. Tucker (1993) used four primary feathers of Harris hawk to study feather tip slots with Clark Y tip made of balsa wood in the shape of a Clark Y airfoil. At an angle of attack of $10.5^{\circ}$ feather tips increased L/D ratio from 4.9 to 10.1 and the total drag reduction was found to be $12 \%$ compared to a hypothetical wing. A Harris hawk glided freely inside a wind tunnel with clipped and unclipped wingtips. It was found that the bird with slotted (unclipped) wing tips had a drag of $70-90 \%$ of the drag of the bird with clipped wing tips. The value of induced drag factor was 0.56 for unclipped birds compared to 1.10 for clipped feather birds (US7900876 B2, 2007; Lockwood, Swaddle, \& Rayner, 1998; Norberg, 2012; Sachs \& Moelyadi, 2006; Swaddle \& Lockwood, 2003). Such results are also reported by various other researchers (US7900876 B2, 2007; Lockwood, Swaddle, \& Rayner, 1998; Norberg, 2012; Sachs \& Moelyadi, 2006; Swaddle \& Lockwood, 2003). Whitcomb (1976) developed the concept of winglets, to reduce induced drag, followed by the development of blended winglet, spiroid winglet, grid winglet, wingtip sail, and wingtip blowing with different modifications within them to improve the aerodynamic behaviour of aircraft (Siddiqui et al., 2017).

Similarly, investigations have been done by prototyping bird inspired rigid wing tips that work as multi winglets. Multi winglets as a prototype of bird feather tips were studied and found to diffuse the vortices. The winglets were rigid with adjustment to change the angle of attack (Smith et al., 2001). (Cerón-Muñoz, Catalano, \& Coimbra, 2008) experimented on winglets with variable cant angles as an active control surface and found winglets affecting the moment axes about multiple-axis providing controlled flight. Three different configurations: delta tip, winglet, and Hoerner tip were tested and found to reduce the induced drag through slots at different cant angles (Cerón-Muñoz, Catalano, \& Coimbra, 2008). Weierman (2010) investigated six different multi-winglets on a half-body model. The device showed a $32.5 \%$ increase in Oswald efficiency factor which increased the aerodynamic efficiency by $7 \%$. For the use in UAVs, Whitcomb and blended winglet were studied for optimization with VLM (Vortex lattice method) at low Reynolds number. The study showed that L/D ratio increased at lower cant angles and large radius while the angle of attack influences the bending moment (Weierman, 2010). Sohn \& Chang (2012) investigated square cut, simple fairing and Whitcomb wingtips on a half wing model. They noticed diverse vorticity formation at different angles of attack. However, Whitcomb winglets surpass others in vorticity reduction. 
A half body model of a trainer aircraft was tested with wingtip blowing and fixed and adaptive multi-winglets. All of them reduce the drag, but multi-winglets achieved the maximum reduction (Céron-Muñoz et al., 2013). Giuni \& Green (2013) using NACA 0012 rectangular wing investigated the initial formation and development of vertical vortex on round and square wingtips by flow visualization. First, the fluctuation was seen due to rolling up of vorticity and second by the amalgamation of primary and secondary vortices.

It seems from the available open literature review that aerodynamics of rigid and flexible spiral shape wing tips with slots has not yet been studied. This paper investigates the aerodynamic behavior of tips using rigid and flexible spiral shapes with slots. A straight flat plate wing with an aspect ratio of 3 is used as the base wing to analyze the aerodynamic behavior of wing tips. This aspect ratio wing has been used first, due to available benchmark experimental data for validation and Second, since UAV's (Unmanned Air vehicle) and MAV's (Micro air vehicle) work between $2 \leq$ AR $\leq 6$ (Ananda, Sukumar, \& Selig, 2015).

The objective of this paper is first to analyze the similar behavior of the several wing tips prepared for the experiments and to find out the best performing wing tip configuration. Secondly, to compare the best-performing wing tip to other forty different wingtip models available in the literature which were analyzed for the same purpose regarding L/D.

\section{Method}

\section{Model description}

Description of base model. A flat plate straight half wing of aspect ratio three was used as the base wing. The chord length (c) of the base wing is $264 \mathrm{~mm}$ and span $804 \mathrm{~mm}$. The base wing was prepared to keep the leading edge round and trailing edge sharp as shown in Figure 1. The thickness to chord ratio of the base wing is $2.72 \%$ which is close to $2.6 \%$ used by Pelletier \& Mueller (2000), Shields \& Mohseni, (2012) but less than $4.3 \%$ of Ananda, Sukumar, \& Selig (2015). This specific $\mathrm{AR}=3$ base wing was used so that the force balance data of the clean wing could be validated against the experimental results of the reported data. 

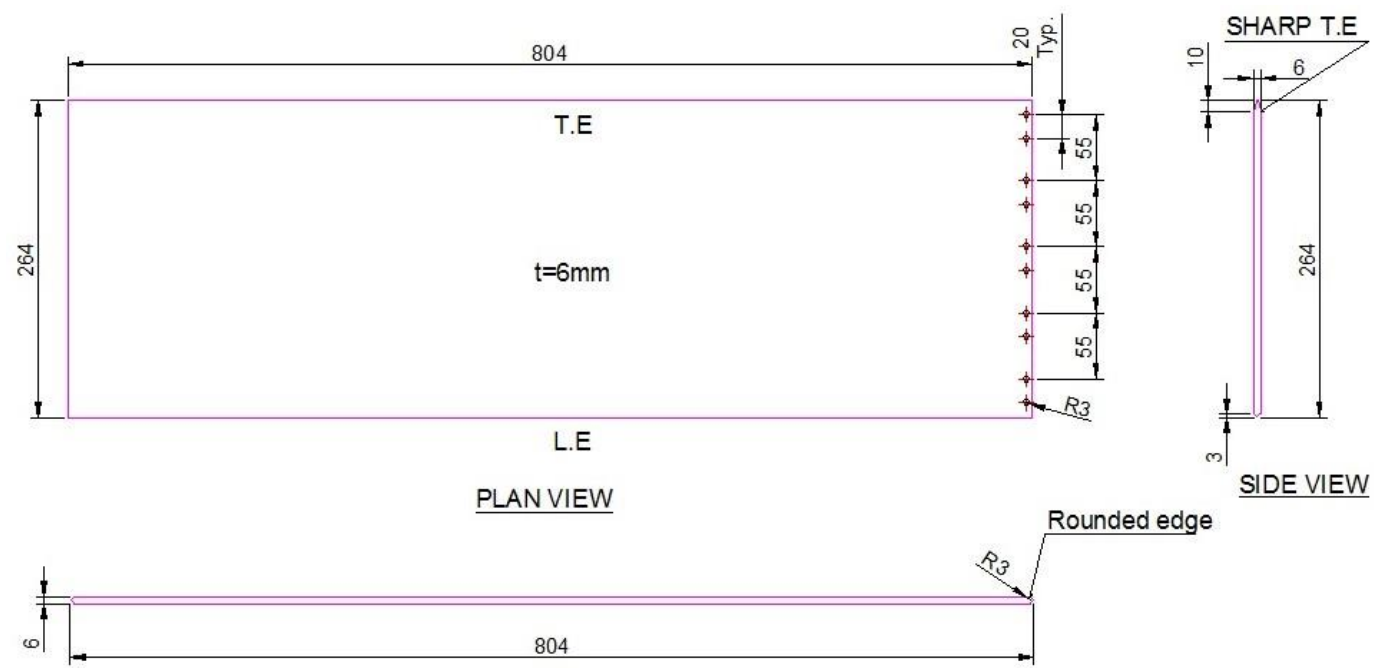

FRONT VIEW

Figure 1. Base wing model.

\section{Description of Wingtips}

Wing tips inspired by the spiral shape of bird feathers as shown in Figure 2 have been considered for investigation in this paper. In the formation of the spiral shape, the first five primary feathers (from leading as the first to the trailing side, fifth, play an essential role.

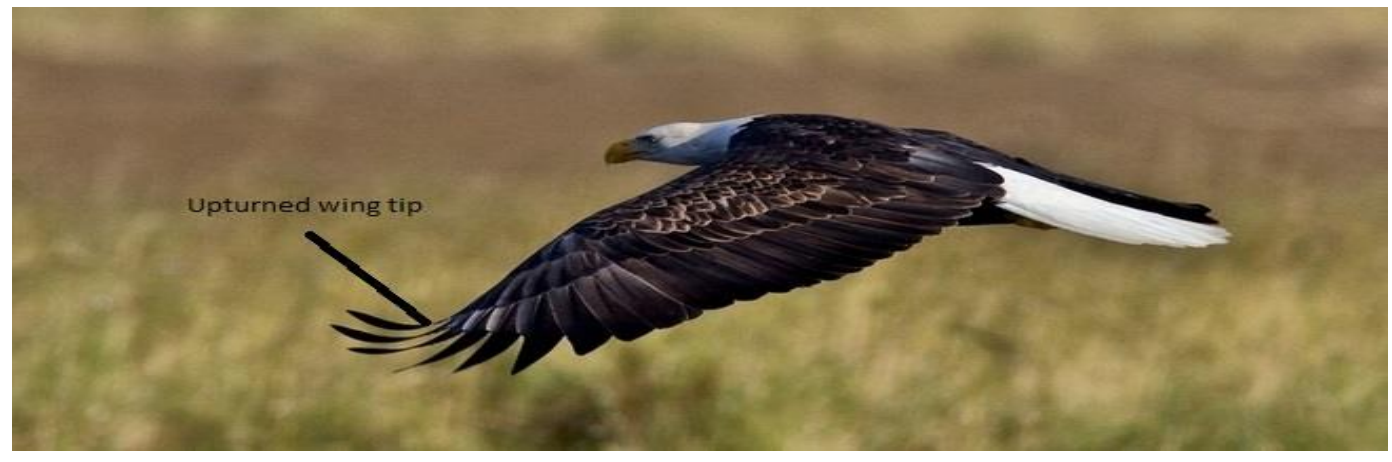

Figure 2. The upturned (spiral) shape (https://biology.stackexchange.com) 
Four types of wing tips have been considered to compare the behavior of flexible and rigid tips inspired by birds. They are denoted as, Flexible curved tip, Flexible flat tip, Rigid curved tip and Rigid flat tip. For the actual dimensions, Emargination length is considered that defines the stepped down width of feather from root to tip as shown in Figure 3. Adult Golden Eagle primary feather wing tips have been taken from Trail (2014) to select the dimensions. Each type of tip has five prototypes (from the first to the fifth bird tip) in close dimensional relation to the actual bird as described in Figure 4 and Tables $2 \& 3$. All are made of aluminum having different thickness. However, the dimensions are approximate.

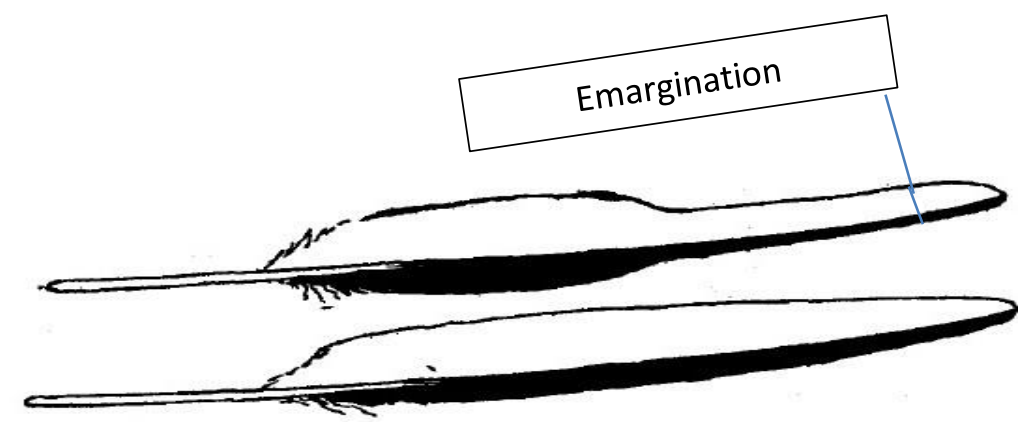

Figure 3. Buzzard feather (above) and Golden plover (below) (Buzzard flies above the ground showing emargination which forms slotted wing tip, but that is not the case with Golden plover flying above the sea. (Graham, 1932)

As per Bachmann et al. (2012), the value of $E$ for pigeon and owl feathers ranges between 4.14-6.93 GPa, but according to Macleod (1980), Purslow \& Vincent (1978) modulus of elasticity vary between 0.045 and $10 \mathrm{Gpa}$. The second moment of area decreased towards wing tips and was higher within 10-20\% length of the feather (Bachmann et al., 2012). In the experiments, Aluminium is used having a modulus of elasticity of $70 \mathrm{GPa}$ and thickness $0.4 \mathrm{~mm}$ with a variable second moment of the area throughout the length for all curved tips. The low thickness makes the tips flexible.

Flexible and rigid flat wing tips are also studied. Flat tips of $1 \mathrm{~mm}$ thickness are considered as flexible and $2 \mathrm{~mm}$ thickness as rigid. $1 \mathrm{~mm}$ thickness is chosen for two reasons; first, a $0.4 \mathrm{~mm}$ flat tip even at low wind speeds takes an unexpected curved shape that cannot be considered as flat. Secondly, the results could be compared with Serdar (2013), Rojratsirikul et al. (2009), Rojratsirikul et al. (2010) and (Graham, 1932) who used 1mm thick plate in their experiments. In all the arrangements, tips are connected to the base wing in the same manner as the bird feather sequencing from the leading (First) to the trailing (Fifth) tip. 

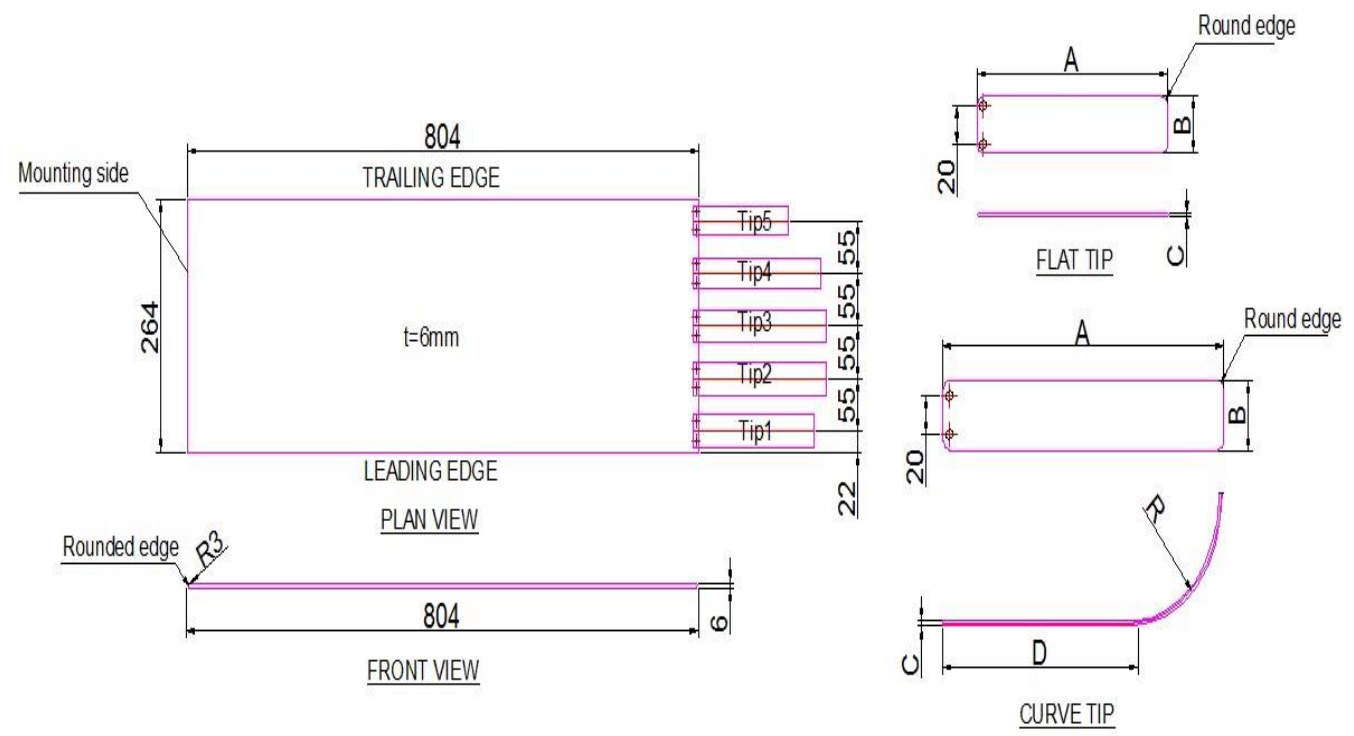

Figure 4. Details of tip used (Dimensions of marked symbols A, B, C, D, and R are given in Table $1 \& 2$.

Table 1

Flat tip details reference to Figure 4

\begin{tabular}{|c|c|c|c|c|c|c|}
\hline Description & \multicolumn{6}{|c|}{ Flat Tips } \\
\hline $\begin{array}{l}\text { Nomenclature of } \\
\text { Tips }\end{array}$ & \multicolumn{3}{|c|}{ Flexible flat tips } & \multicolumn{3}{|c|}{ Rigid flat tips } \\
\hline Dimensions (mm) & $\mathrm{A}$ & B & $\mathrm{C}$ & $\mathrm{A}$ & $\mathrm{B}$ & $\mathrm{C}$ \\
\hline Tip 1 & 190 & 35 & 1 & 190 & 35 & 2 \\
\hline Tip 2 & 210 & 35 & 1 & 210 & 35 & 2 \\
\hline Tip 3 & 210 & 35 & 1 & 210 & 35 & 2 \\
\hline Tip 4 & 200 & 30 & 1 & 200 & 30 & 2 \\
\hline Tip 5 & 150 & 30 & 1 & 150 & 30 & 2 \\
\hline Material & \multicolumn{6}{|c|}{ Aluminum } \\
\hline $\begin{array}{l}\text { Modulus of } \\
\text { Elasticity }\end{array}$ & \multicolumn{6}{|c|}{$70 \mathrm{GPa}$} \\
\hline
\end{tabular}


Table 2

Details of curved tips, reference to Figure 4

\begin{tabular}{|c|c|c|c|c|c|c|c|c|c|c|}
\hline \multirow{2}{*}{$\begin{array}{l}\text { Descriptio } \\
\mathrm{n} \\
\text { Nomenclat } \\
\text { ure of tips }\end{array}$} & \multicolumn{10}{|c|}{ Curved Tips } \\
\hline & \multicolumn{5}{|c|}{ Flexible curved tip } & \multicolumn{5}{|c|}{ Rigid curved tip } \\
\hline $\begin{array}{l}\text { Dimension } \\
(\mathrm{mm})\end{array}$ & $\mathrm{A}$ & $\mathrm{B}$ & $\mathrm{C}$ & $\mathrm{D}$ & $\mathrm{R}^{*}$ & $\mathrm{~A}$ & $\mathrm{~B}$ & $\mathrm{C}$ & $\mathrm{D}$ & $\mathrm{R} *$ \\
\hline Tip 1 & 190 & 35 & 0.4 & 90 & 100 & 190 & 35 & 2 & 90 & $\begin{array}{c}10 \\
0\end{array}$ \\
\hline Tip 2 & 210 & 35 & 0.4 & 150 & 70 & 210 & 35 & 2 & $\begin{array}{c}15 \\
0\end{array}$ & 70 \\
\hline Tip 3 & 210 & 35 & 0.4 & 150 & 70 & 210 & 35 & 2 & $\begin{array}{c}15 \\
0\end{array}$ & 70 \\
\hline Tip 4 & 200 & 30 & 0.4 & 110 & 90 & 200 & 30 & 2 & $\begin{array}{c}11 \\
0\end{array}$ & 90 \\
\hline Tip 5 & 150 & 30 & 0.4 & 80 & 70 & 150 & 30 & 2 & 80 & 70 \\
\hline Material & & & \multicolumn{6}{|c|}{ Aluminum } & & \\
\hline $\begin{array}{l}\text { Modulus of } \\
\text { Elasticity }\end{array}$ & & & \multicolumn{6}{|c|}{$70 \mathrm{GPa}$} & & \\
\hline$*$ & \multicolumn{10}{|c|}{$\begin{array}{l}\text { The radius is arbitrary as it is impossible to measure the exact curve } \\
\text { radius of bird feather during flight. However, it is kept as close as } \\
\text { possible }\end{array}$} \\
\hline
\end{tabular}

The dimension of the tips used in the present study can be compared with different types of models used by other researchers which were inspired by bird wing tips to analyze the aerodynamics of wing tips. Smith et al. (2001) have used five winglets each $38.1 \mathrm{~mm}$ chord and $304.8 \mathrm{~mm}$ span mounted on a half wing model. Céron-Muñoz et al. (2013) have used three sail tips with aspect ratios 2.7, 3.1 and 3.5. Beechook \& Wang (2013) used three rectangular tips each of $121 \mathrm{~mm}$ chord and $330 \mathrm{~mm}$ semi-spans. Cosin et al. (2010) have used the same aspect ratios as Céron-Muñoz et al. (2013). Tucker (1993) has experimented on Clark Y tip that has a $113 \mathrm{~mm}$ span and $89 \mathrm{~mm}$ chord, primary feather tip with $100 \mathrm{~mm}$ span and Balsa feather wingtip with $115.6 \mathrm{~mm}$ span and $25.4 \mathrm{~mm}$ chord. 


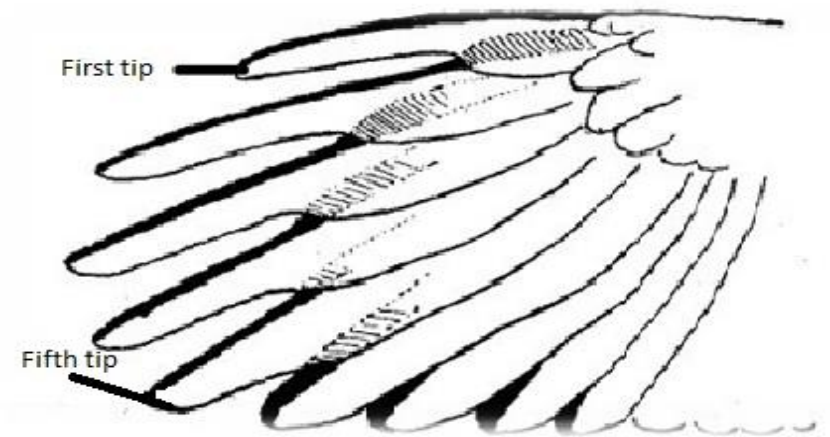

Figure 5. Right wing of Buzzard showing emargination for primary feathers and gaps between them (Graham, 1932)

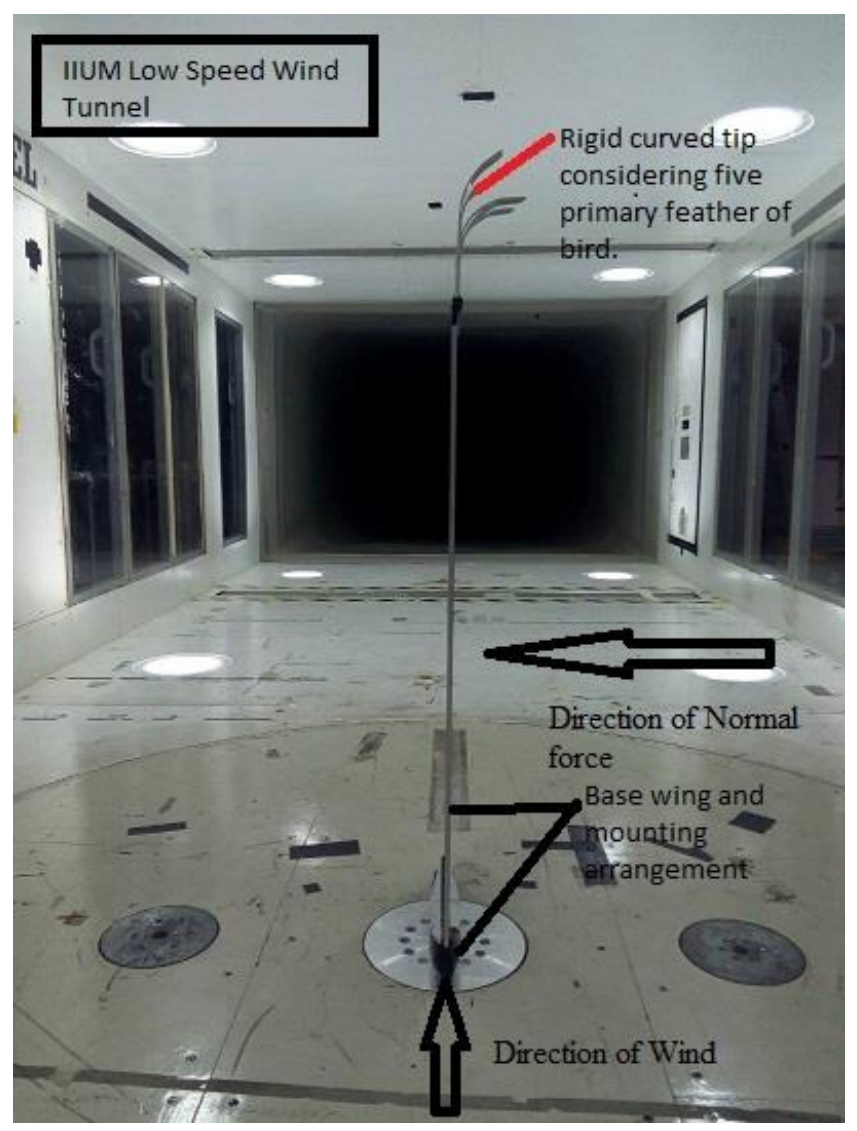

Figure 6. Flat plate wing (Base wing) with rigid curved wing tips of $2 \mathrm{~mm}$ thickness inside the IIUM wind tunnel. 


\section{Facility and force balance}

The experiments were performed in the IIUM low speed closed loop wind tunnel which has a test section of $2.3 \times 1.5 \times 6 \mathrm{~m}$. The maximum airspeed in the wind tunnel is $50 \mathrm{~m} / \mathrm{s}$, and the turbulence intensity of the flow is $<0.11 \%$. Tests were performed at a free stream speed of $20 \mathrm{~m} / \mathrm{s}$. A six component balance was used to measure the forces and moments. The half model normal force has a measurement range of $\pm 2000 \mathrm{~N}$ and has uncertainty of $0.0406 \% \mathrm{FS}$. The axial force has a measurement range of $\pm 700 \mathrm{~N}$ and has uncertainty of $0.049 \% \mathrm{FS}$. The pitching moment has a measurement range of $\pm 250 \mathrm{~N}$. m and has uncertainty of $0.041 \% \mathrm{FS}$. The blockage ratio at maximum alpha is $0.786 \%$.

\section{Validation with benchmark results}

The aerodynamic coefficients of the base wing (flat plate) straight half model were measured and used as validation of the balance data with three different existing data sets available in the literature: Pelletier \& Mueller (2000), Shields \& Mohseni (2012) and Ananda et al. (2015). The thickness to chord ratio of the base wing is $2.72 \%$ which is close to $2.6 \%$ used by Pelletier \& Mueller (2000), Shields \& Mohseni (2012) but less than 4.3\% which Ananda et al. (2015) have used for their experiments. Pelletier \& Mueller (2000) have used a semi-span wing compared to Shields \& Mohseni (2012) who used a full span wing. A half wing model has been used by Ananda et al. (2015). The results are compared in figures 7 to 9 . Measurements were taken for angles of attack -30 to +30 degree to see the effect of negative and post stall characteristics of both base wing and wingtips.

As can be seen in Figure7, the lift curve is close to the results of Pelletier \& Mueller (2000), Shields \& Mohseni (2012) and Ananda et al. (2015). For negative angles of attack, the maximum lift coefficient is around 0.5. Minor difference exists between the stall angle of attack and positive maximum lift coefficient. The flat plate half wing in the IIUM wind tunnel has shown maximum lift at $18^{\circ}$ after which stall starts which is slightly different from the available data. The differences can be attributed to differences in the model, Reynolds number, installation, wind tunnel and balance characteristics.

Similarly, the drag vs. angle of attack curves is close to the data presented in all the three references. Minimum drag is in the range of the theoretically predicted values reported by Ananda et al. (2015). The pitching moment vs. angle of attack curve are close and follow the same trend as the published data. The difference in pitching moment curves can be attributed to several parameters like 
model difference, Reynolds number and minor errors due to wind tunnel, installation and balance characteristics.

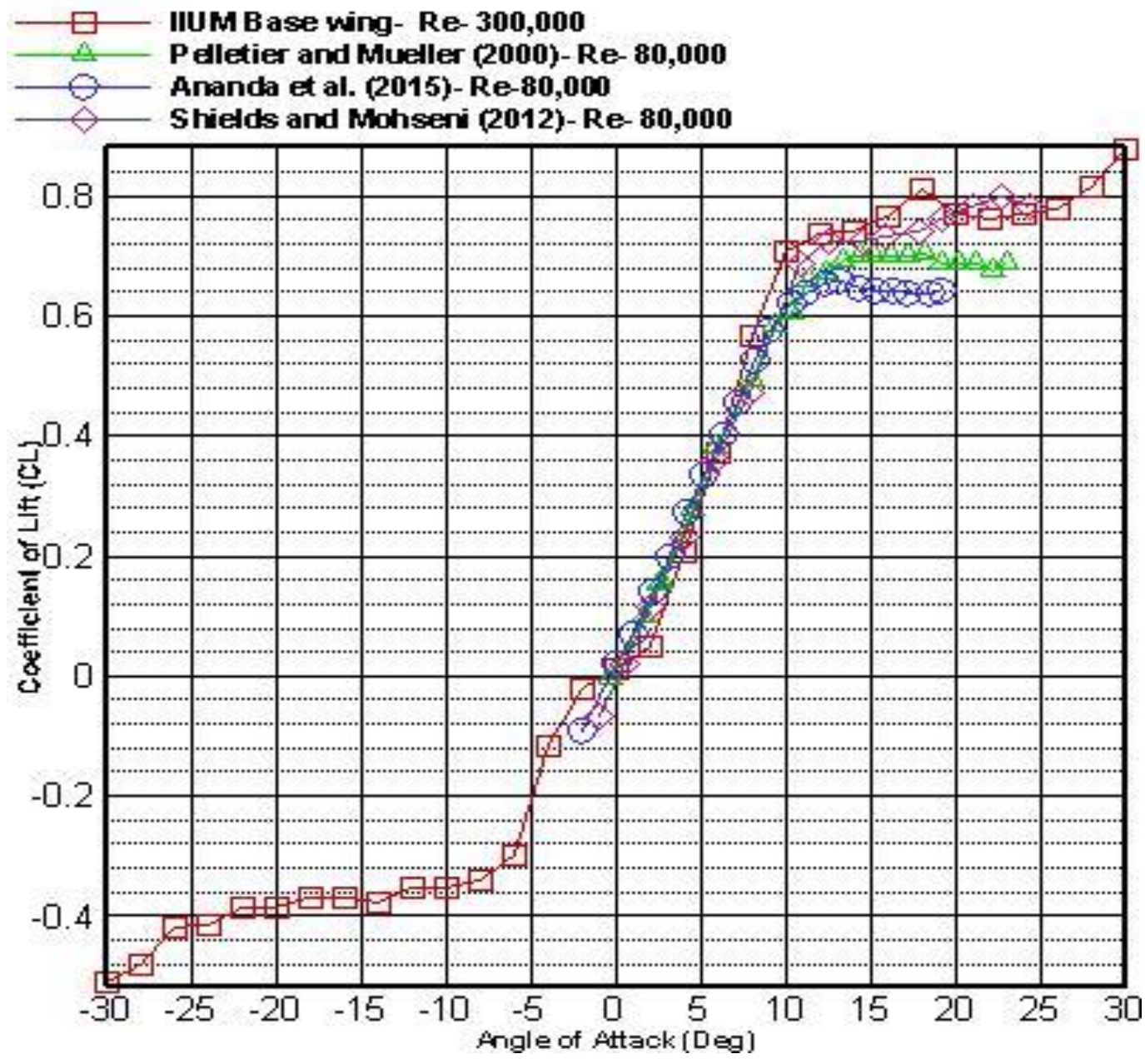

Figure 7. Lift curve validation 


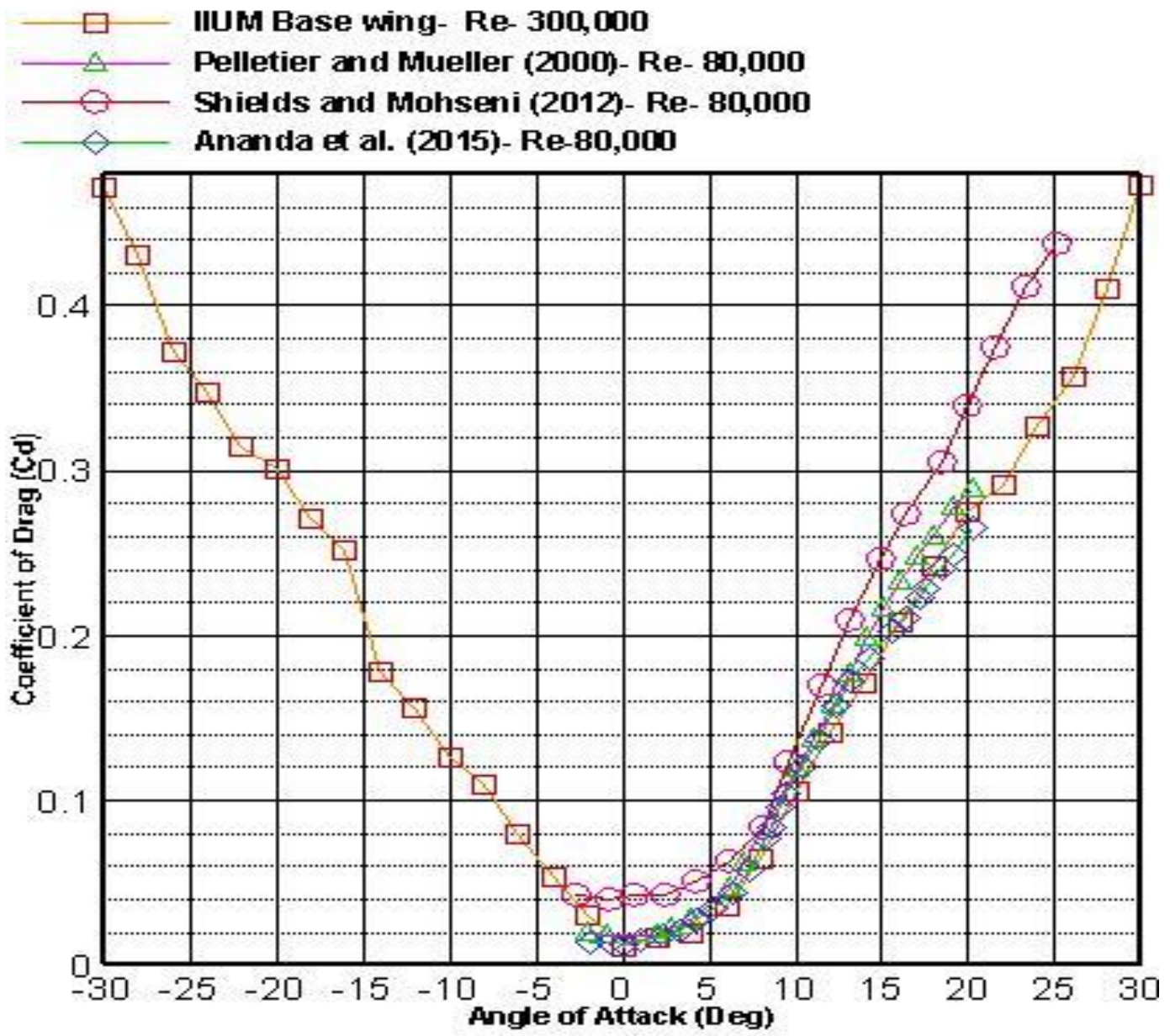

Figure 8. Drag curve validation 


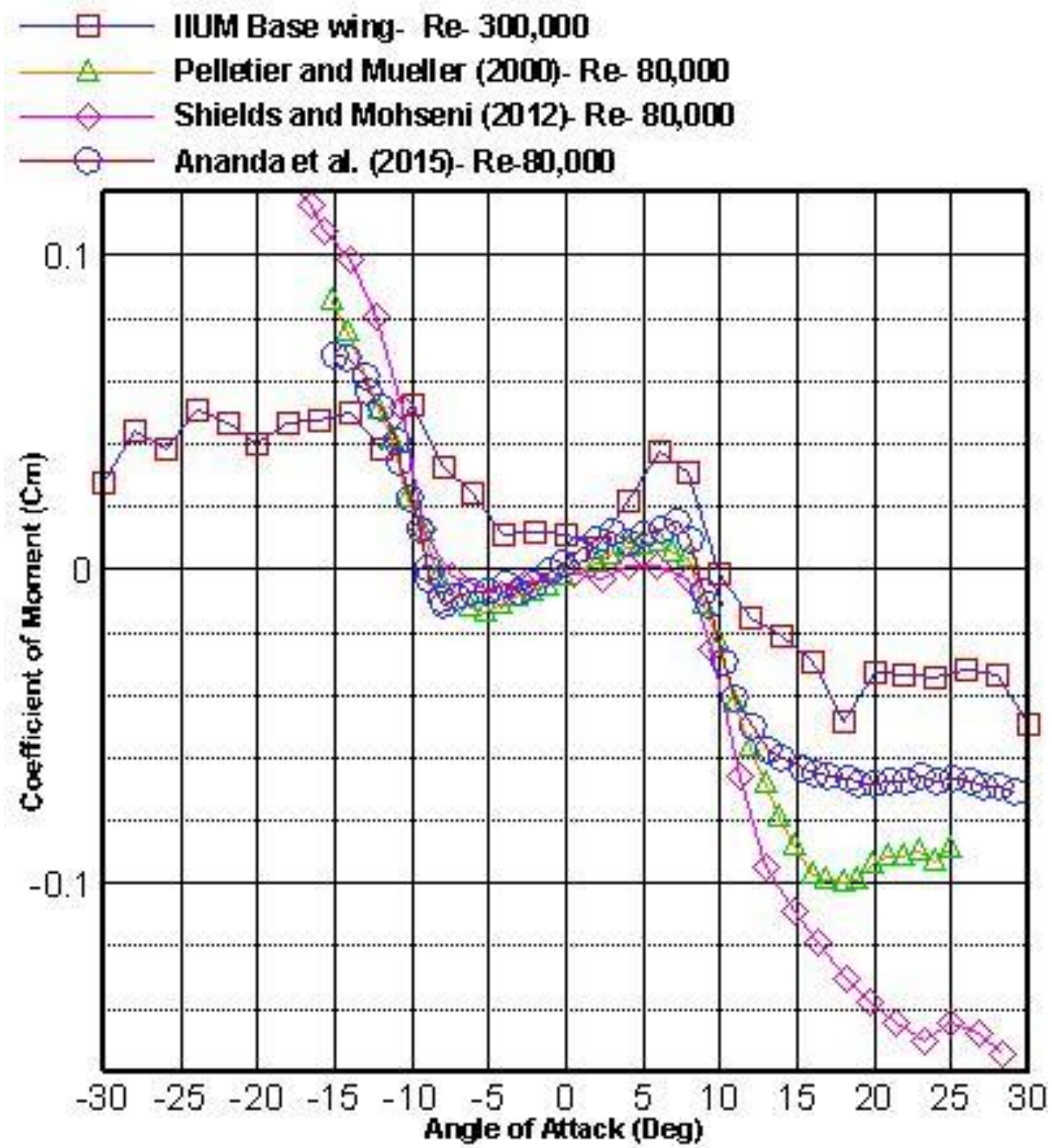

Figure 9. Moment curve validation

\section{Results and Discussion}

In this section results and general observation will be discussed most importantly, maximum lift coefficient, lift curve slope, drag, L/D ratio, and effect on flight performance. 


\section{Lift}

Flexible wing tips. The lift coefficient $\mathrm{C}_{\mathrm{L}}$ is estimated from $\mathrm{L} / \mathrm{q}_{\infty} \mathrm{S}$ where the planform area $S$ in all the cases considered is the base wing planform area. As shown in Figure 10, the maximum value of lift coefficient $\left(\mathrm{C}_{\mathrm{L} \max }\right)$ is 0.85 at $14^{\circ}$ angle of attack for flexible curved tip compared to 0.95 at $16^{\circ}$ angle of attack recorded for flexible flat tips. At $14^{\circ}$ angle of attack, a $14.8 \%$ increase in $\mathrm{C}_{\mathrm{Lmax}}$ coefficient is found for flexible curved tips concerning the base wing. Similarly, the flexible flat tip has shown a $24 \%$ increase in lift coefficient at $16^{\circ}$ angle of attack concerning the base wing.

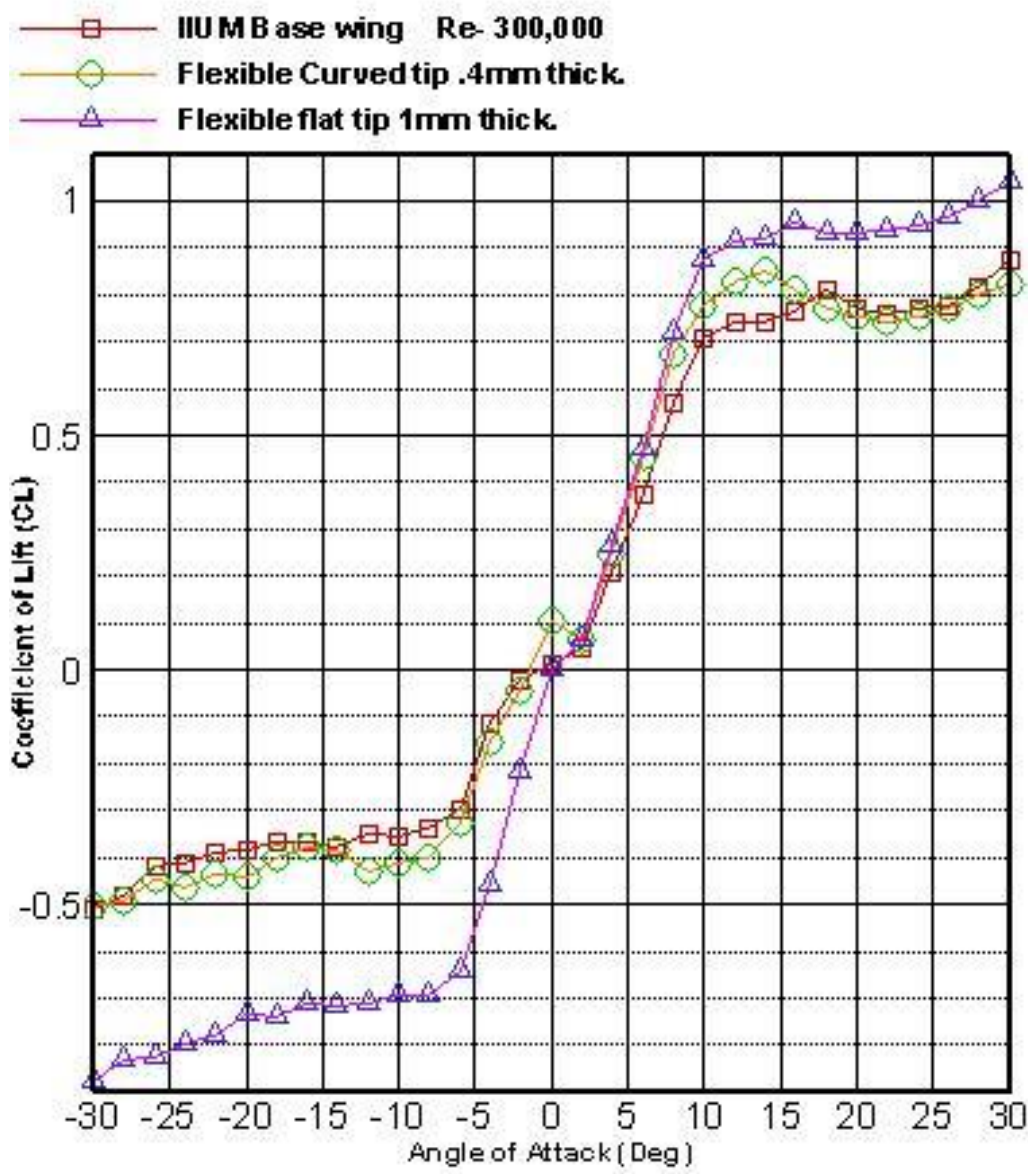

Figure 10. Effect of flexible tips on lift coefficient 
For comparison, Céron-Muñoz et al. (2013) reported the value of maximum lift to be 1.4 at $16-17^{\circ}$ stall angle for multi-winglets at $45^{\circ}, 45^{\circ},-15^{\circ}$ cant angle, that is maximum in fourteen different model tested. Cosin et al. (2010) reported $\mathrm{C}_{\mathrm{Lmax}}$ to be 1.12 at $11^{\circ}$ stall angle for a configuration which has three winglets with cant angles of $30^{\circ}, 15^{\circ}$, and $0^{\circ}$ respectively, that is maximum in six different configurations tested. Smith et al. (2001) reported the maximum value between eleven different configurations tested to be 0.8 with different dihedral angles. As per Withers (1981) $\mathrm{C}_{\mathrm{Lmax}}$ for original bird feather tip is 1.2, but in contrast, Tucker (1993) reported $\mathrm{C}_{\mathrm{Lmax}}$ to be more than 2.5 at $15^{\circ}$ angle of attack. Albertani et al. (2007), while comparing the flexible membrane wing to rigid wing reported $\mathrm{C}_{\mathrm{Lmax}}$ around 1.3 , higher than a rigid wing.

Compared to both original bird tip and its model in these experiments, the value of $\mathrm{C}_{\mathrm{Lmax}}$ for a wing with flexible $0.4 \mathrm{~mm}$ thickness curved tip is lower, but it has higher stall angle which can delay the flow separation, hence less drag at a higher angle of attack.

As observed by Withers (1981) there is an increase in lift slope for primary feather tip of the black vulture. For the base wing in the linear region, the lift slope is around 0.0533 per degree. The lift slope of the wing with flexible curved tip is 0.061 which is an increase of around 14\%. For the wing with flexible flat tips, the lift slope is 0.066 per degree which is an increase of around $23.8 \%$ when compared to the base wing and around $8.1 \%$ increase when compared to wing with flexible curved tips. It concludes that increase in maximum lift coefficient is due to increase in effective aspect ratio (Céron-Muñoz et al., 2013). At a fixed value of the coefficient of lift if AR is increased, induced drag will reduce. So, due to wingtip like of multi-winglets and bird feather tip indeed induced drag decreases as reported by experiments.

Rigid wing tips. The maximum lift coefficient for a wing with rigid curved tips is around 0.79 at $16^{\circ}$ angle of attack and 1.21 at $16^{\circ}$ angle of attack for a wing with rigid flat tips. In comparison to the base wing there is a $3 \%$ increase in maximum lift if rigid curved tips are used, and an increase of $58 \%$ for a wing with rigid flat tips.

Compared to the values reported earlier from the literature, the maximum lift coefficient with tips are in the range 1.12 to 1.5 except for the data of (Tucker, 1993) which is 2.5 but following the trend in wings with flexible tips, a wing with rigid curved tip also has a smaller value of the maximum lift coefficient. On the other hand, both rigid curved and flat tips have shown higher stall angles which can 
delay the separation resulting in lower drag hence less power to overcome total drag.

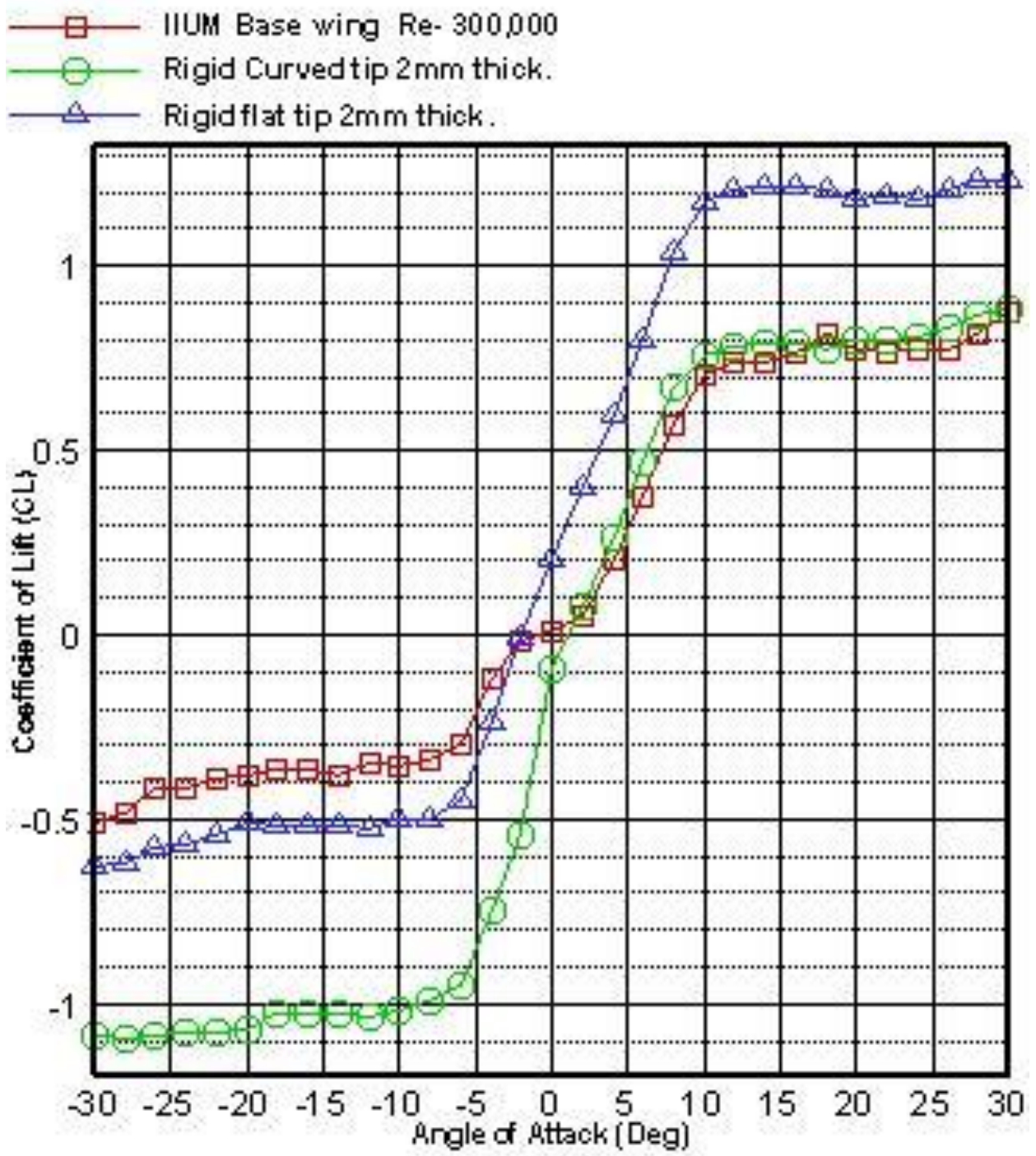

Figure 11. Effect of rigid tips on lift coefficient.

As far as lift slope is concerned, there is an increase in lift slope. For the base wing, the lift slope is around 0.0533 per degree and lift slope for a wing with rigid curved tips is 0.064 per degree which is an increase of around $20 \%$. For rigid flat tips, the lift slope is 0.066 per degree which is an increase of around $42.5 \%$ 
when compared to the base wing and around $18.7 \%$ higher than a wing with flexible curved tips.

It can be concluded that compared to the base wing without any wing tips, the percentage increase in lift coefficient for a wing with flexible curved tip is comparatively low. However, for a wing with rigid curved tips, the increase in lift coefficient is substantially higher.

\section{Drag}

Flexible wing tips. Figure 12, highlights the behaviour of the variation of the drag coefficient of wings with flexible curved wingtips of $0.4 \mathrm{~mm}$ thickness. The minimum drag coefficient of 0.026 is slightly higher than the base wing. The behaviour of the wing with curved flexible wing tips is close to the base wing in the positive range of angle of attack. The minimum drag coefficient value of 0.026 is quite close to that of a black vulture feather tip of 0.024 (Withers, 1981) which is remarkable. Similarly, the value of minimum drag coefficient for a flexible flat tip with $1 \mathrm{~mm}$ thickness is found to be 0.029 at $0^{\circ}$ angle of attack and it is very unusual. For positive angle of attack, the drag coefficient of the wing with $1 \mathrm{~mm}$ thick flat tips is higher than the base wing as well as the wing with curved tips. Beechook \& Wang (2013) reported $\mathrm{C}_{\mathrm{D}}$ for rectangular wing made of NACA 653218 airfoil section with winglet at $0^{\circ}$ angle of attack to be 0.128 at zero cant angles, 0.132 at $30^{\circ}$ cant angle and 0.118 at $45^{\circ}$ cant angle out of ten models. Cosin et al. (2010) reported the value to be 0.046 at $0^{\circ}$ angle of attack for a half model made of NACA 23015 with multi-winglets, minimum out of six models.

Smith et al. (2001) reported the value to be in the range of 0.017-0.037 at a $0^{\circ}$ angle of attack for rectangular wing made of NACA 0012 with multi winglets, minimum from eleven models. The wing with flexible curved tips in the experiments reported here is in very close agreement as reported for real birds determined through experiments. These values are also similar to Cosin et al. (2010) and Smith et al. (2001). Flexible curved tip shows unusual drag increment at the negative side that is due to scattered shape at a negative angle during the experiment. The reason behind high drag coefficient for the flexible flat tip of $1 \mathrm{~mm}$ thickness with increasing angle of attack is due to vorticity generation only horizontally compared to both horizontal and vertical for the flexible curved tip (Tucker, 1993). Experimental result of Albertani et al. (2007) suggests an increase in drag for flexible wings compared to rigid wings.

This seems to be in contrast to the result proposed by Rojratsirikul et al. (2010) while comparing the flexible and rigid wings. They concluded, due to 
oscillations of the membrane, it excites the shear stress that rolls-up the large vortices over the wing and that predict a decrease in drag and delay in the stall. So flexibility can delay the stall as has been reported which can be validated from the current experimental result.

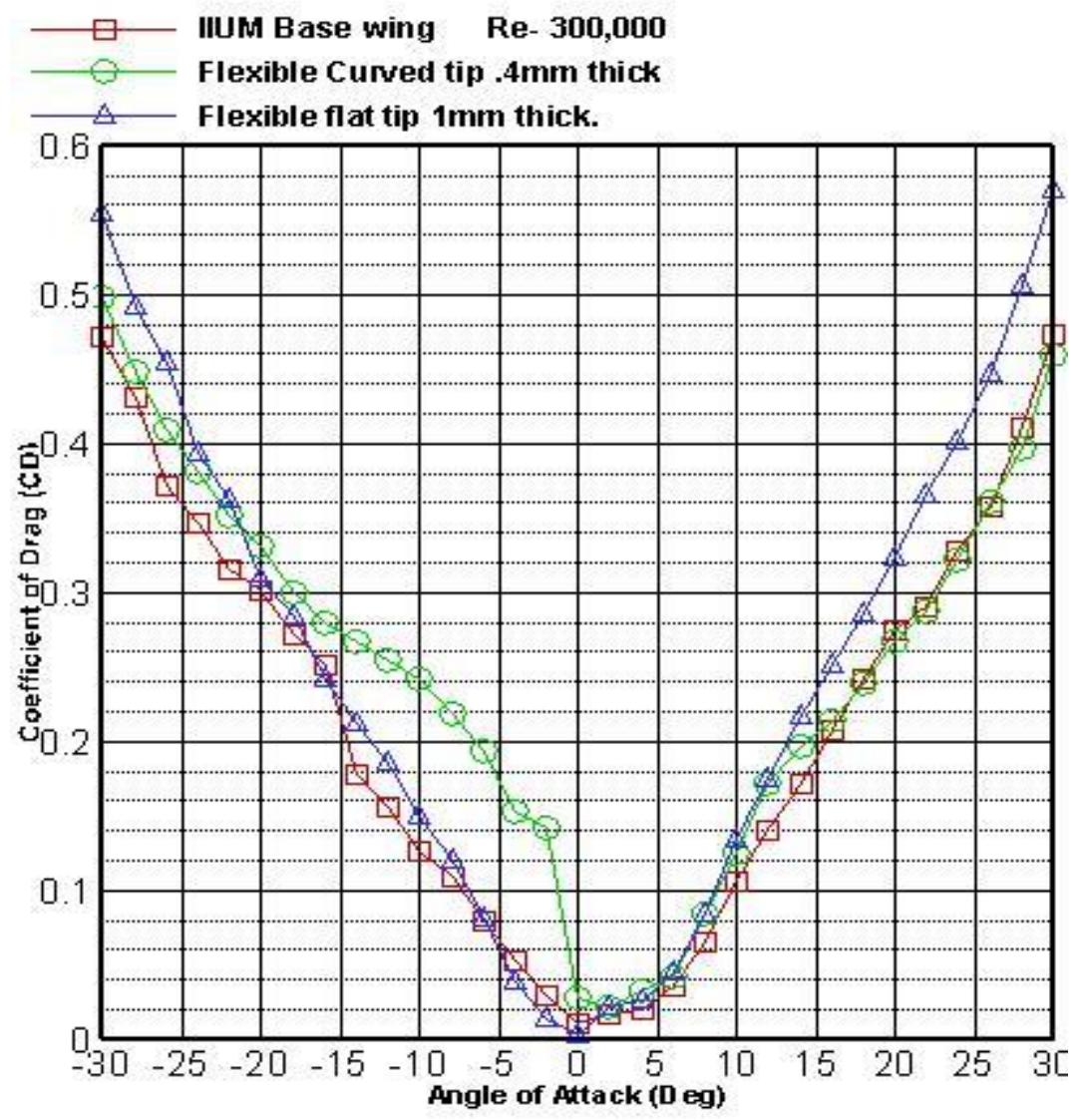

Figure 12. Flexible tips drag vs. angle of attack graph 
Rigid wing tips. The drag behavior of a flat plate wing with rigid curved and flat tips of $2 \mathrm{~mm}$ thickness is shown in figure 13. In the case of flat rigid tips, the drag increases for all angles of attack as compared to the base wing with no wing tips. For rigid curved tips, the drag is slightly higher than the drag for the base wing for all positive angles of attack. In the negative angle of attack range, the drag is higher. This is perhaps due to asymmetry in the curvatures. The value of minimum drag at zero angle of attack is 0.023 for curved wing tips and 0.131 for rigid flat tips. Compared to the base wing value, there is an increase in drag coefficient of 0.012 for rigid curved tips and 0.12 for rigid flat tips.

The above values can be compared to the values reported earlier. It shows that a wing with rigid curved tips has the lowest value of drag coefficient. On the contrary drag coefficient of rigid flat tips lie in the range from 0.017 to 0.138 . The value of $C_{D}$ at zero angle of attack for a flat tip is quite similar to what has been reported by Beechook \& Wang (2013), but that is far greater than the value reported for the real bird feather which is 0.024 .

The reason behind such large drag coefficients in flat tip lies in one directional vorticity dispersion due to sharp edges because in slotted wingtips each tip works as a separate airfoil creating staggered vorticity affecting the preceding tip. In curved wing tips because of their non-planar configuration, vorticity generation is both horizontal and vertical, the drag is much lower. Low values of drag in a wing with rigid curved tips are due to vorticity dispersion both horizontally and vertically that is not present in the flat tip configuration (Tucker, 1993).

\section{L/D Ratio}

Flexible wing tips. According to figure 14, for Reynolds, number $3 \times 10^{5}$, the $(\mathrm{L} / \mathrm{D})_{\max }$ for a wing with flexible curved tips is 10.7 at a $6^{\circ}$ angle of attack manifesting an increase of 5\% from the base wing. For flexible flat tips, the $(\mathrm{L} / \mathrm{D})_{\max }$ is 10.3 occurring again at a $6^{\circ}$ angle of attack, a $1 \%$ increase compared to the base wing which is 10.2 at a $6^{\circ}$ angle of attack. The (L/D) $\max$ for flexible curved tips is close to the value reported by Tucker (1993) which is 10.1. Apart from this, as per Cosin et al. (2010), (L/D), max is around 12.3 at an angle of attack around $4^{\circ}$ for a configuration which has three winglets with cant angles of $30^{\circ}, 15^{\circ}$ and $0^{\circ}$.

Similarly, Smith et al. (2001) recorded the highest value of (L/D) $\max$ as 10.8 at a $3.5^{\circ}$ angle of attack which is highest among three experiments with different variables and fixed wingtip. A wing with flexible curved tips has shown an (L/D) $\max$ very close to the values obtained by experiments on real birds and their prototypes with different cant and dihedral angles. 
Rigid wing tips. The lift to drag ratio for a wing with rigid tips is shown in figure 15 , for a Reynolds number of $3 \times 10^{5}$. The value of maximum lift to drag ratio $(\mathrm{L} / \mathrm{D})_{\max }$ for a wing with rigid curved tips is 12.5 at a $4^{\circ}$ angle of attack. For rigid flat tips, the value of (L/D) $\max$ is 4.2 at an $8^{\circ}$ angle of attack. Compared to the values of the base wing, rigid curved tip causes an increase of $20 \%$ in $(\mathrm{L} / \mathrm{D})_{\max }$, but in contrast, a wing with rigid flat tips shows a $60 \%$ decrease from the base wing value. Compared to the values of (L/D) $\max$ reported from the existing literature above, the $(\mathrm{L} / \mathrm{D})_{\max }$ of a wing with rigid curved tips surpasses all previously reported tips.

\section{Effect of flexibility}

Rojratsirikul et al. (2009), Rojratsirikul et al. (2010), Rojratsirikul et al. (2011) conducted studies on rectangular wings with membrane surfaces. They reported that oscillation of membrane shed strong vortices in the wake, and suggested that the flexibility of wing surface material can delay the stall. Static stability and lift will increase due to flexibility of material (Withers, 1981). Due to pressure difference feather of bird bends spanwise and will exert force to lift the front side relative to back, especially at wing tips which has less strength that may act as end plate (Withers, 1981). There can be high thrust by the spanwise bending and high effective angle of attack but too much flexibility may deteriorate the aerodynamic behaviour at root and tip (Aono et al., 2009).

The aeroelastic parameter used by Smith \& Shyy (1996) is defined as:

$$
\pi=\left(\frac{E t}{q c}\right)^{1 / 3}
$$

$\mathrm{E}$ is elastic constant, $\mathrm{t}$ thickness, $\mathrm{q}$ dynamic pressure and $\mathrm{c}$ is the chord length. The aeroelastic parameter is a strong function of thickness and velocity. Greater the velocity smaller will be the value of the aeroelastic parameter. Flexibility creates oscillation and when Reynolds number increases, aeroelastic parameter will decrease which will shift the shear layer close to wing surface while the camber will increase (Gordnier, 2009). 


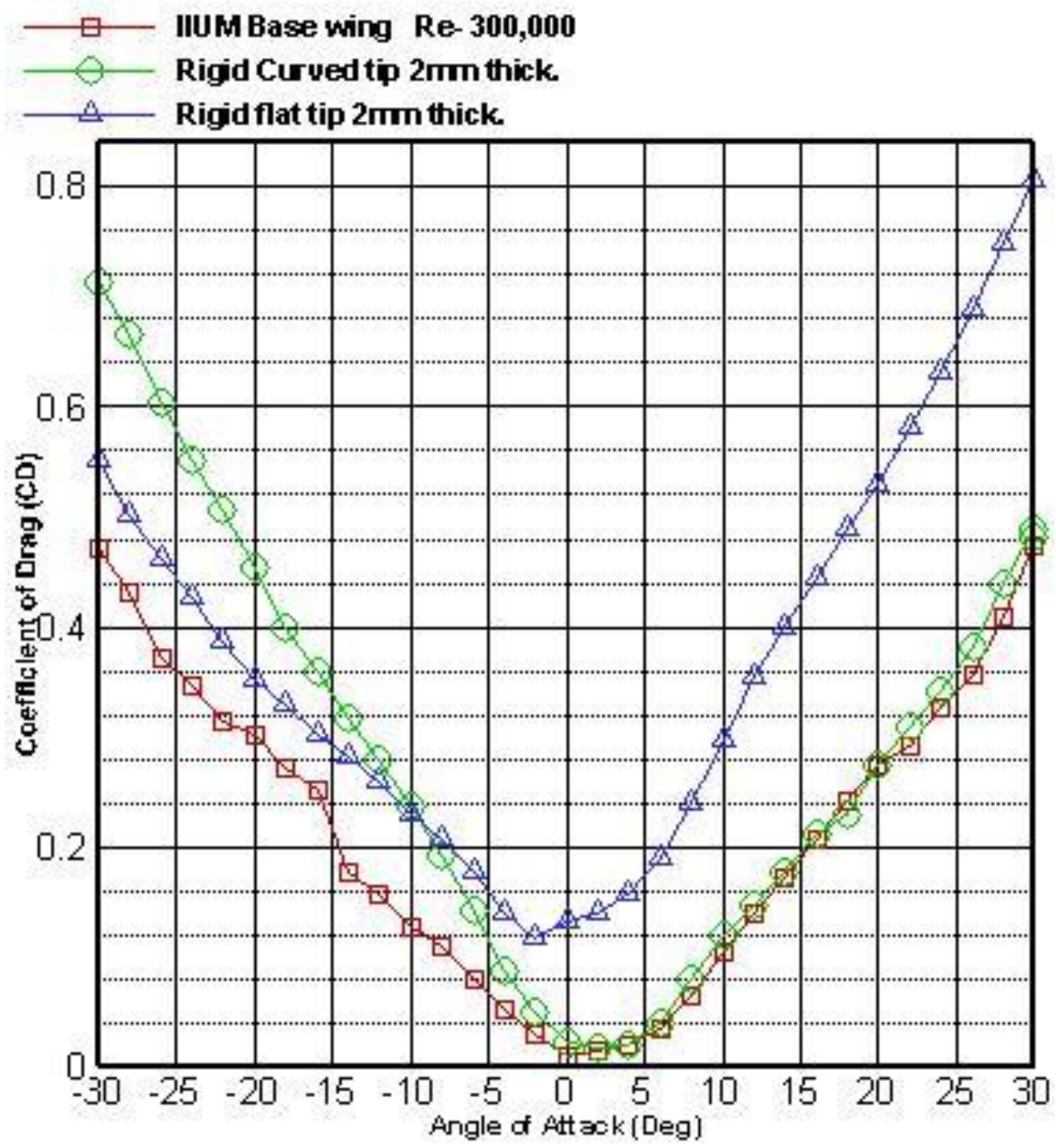

Figure 13. Rigid tips drag vs angle of attack graph 


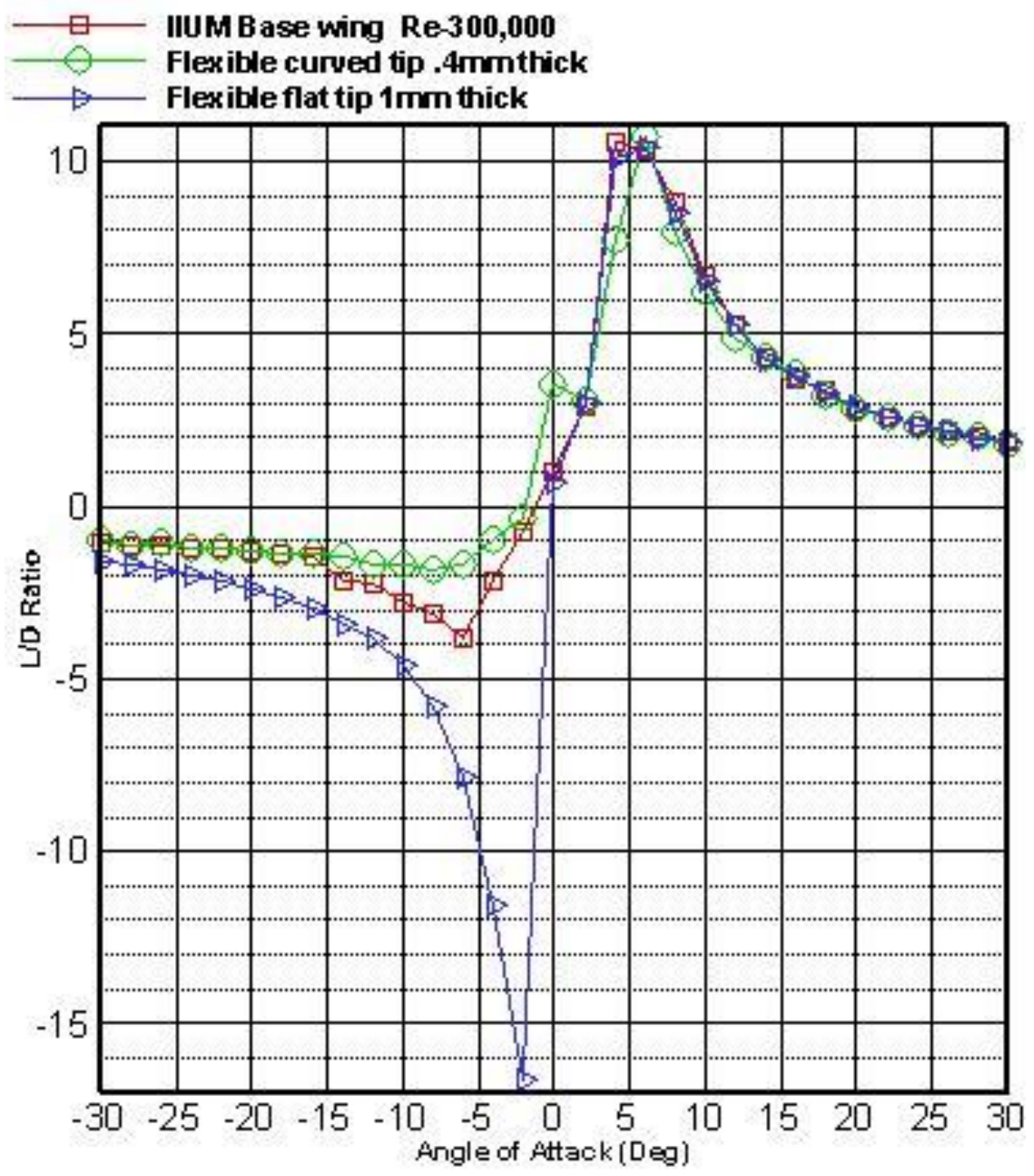

Figure 14. Flexible tips behaviour between L/D ration and angle of attack 


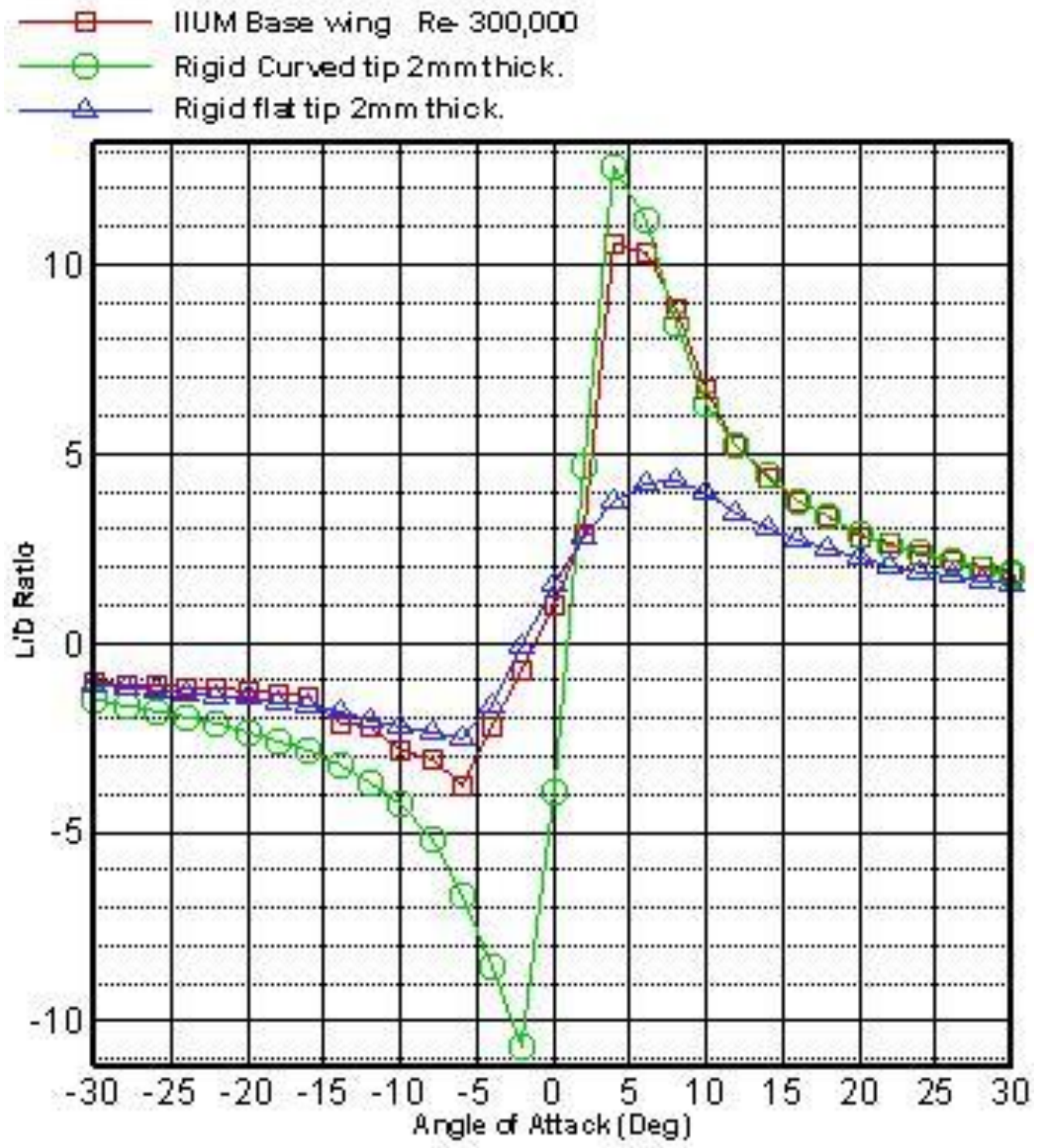

Figure 15 Rigid tips behaviour Graph between L/D vs angle of attack

At a fixed value of aeroelastic parameter, significant decrease in the size of the separation zone is seen (Gordnier, 2009). For flexible curved tip, the value of aeroelastic parameter is around 148.2 while it is 201.1 for flexible flat tip. Both the tips have same Reynolds number, chord length and dynamic pressure except the 
value of thickness which is $0.4 \mathrm{~mm} \& 1 \mathrm{~mm}$ respectively. Due to oscillation, length of chord will vary its projected area to air, and as reported by (Withers, 1981) the camber will increase which will change the value of the aeroelastic parameter during flight. It does not depend on aspect ratio so any variation in span and shape will not affect the overall dynamics of the aeroelastic parameter. It suggests that individual tips work as separate airfoils creating its own aerodynamic coefficients $\&$ aspect ratio. This has been suggested for individual primary feathers of birds also (Combes \& Daniel, 2003; Pennycuick \& Lock, 1976).

However, flexibility has a by default advantage, and that is: a portion of energy generally lost due to vorticity now will be stored in the form of elastic strain energy and for real birds is a well-known fact (Combes \& Daniel, 2003; Pennycuick \& Lock, 1976). It was reported by Blick et al. (1975) that each feather tip probably has its individual vortex which reduces maximum vorticity compared to non-slotted wing tips. Based on this fact both flexible curved tips and flat tips reduce the induced drag.

\section{Comparative Discussion}

Relative merits and demerits of each flexible and rigid wingtip have been discussed in subsequent sections. The results are tabulated in Table 4 to show the overall comparison of aerodynamic coefficients:

Table 3

Comparison of Flexible and Rigid wing tips

\begin{tabular}{|l|c|c|c|c|}
\hline Model & $\begin{array}{c}\text { Flexible } \\
\text { Curved tip }\end{array}$ & $\begin{array}{c}\text { Flexible } \\
\text { Flat tip }\end{array}$ & $\begin{array}{c}\text { Rigid } \\
\text { Curved tip }\end{array}$ & $\begin{array}{c}\text { Rigid Flat } \\
\text { tip }\end{array}$ \\
\hline Thickness (t) & $.4 \mathrm{~mm}$ & $1 \mathrm{~mm}$ & $2 \mathrm{~mm}$ & $2 \mathrm{~mm}$ \\
\hline Dynamic pressure & 245 & 245 & 245 & 245 \\
\hline $\begin{array}{l}\text { Aeroelastic } \\
\text { parameter }\end{array}$ & 148.2 & 201.1 & Infinite & Infinite \\
\hline $\begin{array}{l}\text { Drag at zero } \\
\text { degree angle of } \\
\text { attack (C) }\end{array}$ & 0.026 & 0.029 & 0.023 & 0.131 \\
\hline $\begin{array}{l}\text { Maximum lift } \\
\text { coefficient (Clmax) }\end{array}$ & 0.85 & 0.95 & 0.79 & 1.21 \\
\hline $\begin{array}{l}\text { Maximum L/D } \\
\text { ratio }\end{array}$ & 10.7 & 10.3 & 12.5 & 4.2 \\
\hline $\begin{array}{l}\text { Stall angle of } \\
\text { attack }\end{array}$ & $14^{\circ}$ & $16^{\circ}$ & $16^{\circ}$ & $16^{\circ}$ \\
\hline
\end{tabular}


Table 4

Comparison between Rigid curved tip and existing tip model with respect to $L / D$ ratio

\begin{tabular}{|c|c|c|c|}
\hline Sr. No. & Description & $\begin{array}{l}\text { Number of } \\
\text { models tested }\end{array}$ & $(\mathrm{L} / \mathrm{D})_{\max }$ \\
\hline 1 & $\begin{array}{l}\text { (Céron-Muñoz et al., } \\
\text { 2013) }\end{array}$ & 14 & 11.7 \\
\hline 2 & (M. J. Smith et al., 2001) & 11 & 10.8 \\
\hline 3 & (Cosin, R. et al., 2010) & 6 & 11.6 \\
\hline 4 & $\begin{array}{l}\text { (Beechook \& Wang, } \\
\text { 2013) } \\
\text { (Only experimental) }\end{array}$ & 5 & 3.9 \\
\hline 5 & (Tucker, 1993) & 3 & 10.3 \\
\hline 7 & $\begin{array}{l}\text { (Withers, 1981) Only } \\
\text { primary vulture is } \\
\text { considered from total of } \\
14 \text { other bird }\end{array}$ & 1 & $\begin{array}{l}17 \\
\text { (That is due to } \\
\text { original bird tips } \\
\text { of primary } \\
\text { vulture, other } \\
\text { than this } 12 \text { bird } \\
\text { tips have less } \\
\text { value than L/D- } \\
\text { 9) }\end{array}$ \\
\hline 8 & Rigid curved tip & 1 & 12.5 \\
\hline
\end{tabular}

It can be seen that drag values at zero angle of attack are quite the same except for rigid curved tips. These values are close to the values reported through experiment performed on real birds and dead bird feathers directly. Maximum lift coefficient of flexible curved tips is higher than the rigid curves tip but less than flat tips. Rigid flat tips show the maximum lift coefficient a $42 \%$ increase when compared to flexible curved tip, a $27 \%$ increase when compared with flexible flat tips, and a $53 \%$ increase when compared with rigid curved tips. Based on this fact it can be said that stall speed will be minimum for rigid flat tips compared to the other three. Induced drag will also be higher for maximum lift coefficients, but it will also depend on the way each tip disperses the vorticity. For curved tips it has both horizontal and vertical dispersion compared to flat tips that have only horizontal dispersion. Similarly, the rigid flat tips show the highest $\mathrm{C}_{\mathrm{D} 0}$. The flexible curved tip has $80 \%$ smaller, flexible flat tip has $97.7 \%$ and rigid curve tip has $82.4 \%$ less drag compared to rigid flat tips. The reason behind the low values of drag in 
flexible and rigid curved tip is due to vorticity dispersion in both the horizontal and vertical directions (Munk, 1923) that is absent in the flat tip configuration. However, the behaviour of flexible flat tips producing low drag coefficient is very unusual.

Most of the performance characteristic depends on the value of lift to drag ratio $(\mathrm{L} / \mathrm{D})$. As per the data, rigid curved tip performed best in terms of $L / \mathrm{D}_{\max }$. Rigid curved tip has the value of $\mathrm{L} / \mathrm{D}_{\max }$ of 12.5 which shows a $16.8 \%$ increase with reference to flexible curved tip, a $21.3 \%$ increase compared to flexible flat tip and $197 \%$ higher than a rigid flat tip. All the performance parameters are better for rigid curved tips compared to the values of flexible wing tips.

More than forty different types of models haven been compared with rigid curved tips and are found to be less efficient. It means although there is a benefit with flexible curved tip in some aspects, rigid curved tip surpassed flexible as well as other forty different models with varying cant angle, dihedral angle, aspect ratio, and thickness in terms of L/D ratio. Data from the other forty models and the current rigid curved tip model is presented in Table 4 below.

Three other tips which are studied in this paper with the rigid curved tip should also be considered in this comparison. To conclude the discussion, it is found that using low aspect ratio base wing, rigid curved tip seems to show the greatest possibility of L/D improvement. Based on the aerodynamic coefficients discussed in earlier sections on flexible and rigid tips, the thrust required is inversely proportional to $\mathrm{L} / \mathrm{D}$ but power required is inversely proportional to $\frac{C L^{\frac{3}{2}}}{C_{D}}$ which suggest a decrease in both the cases at increased L/D ratio. Gliding angle will reduce for maximum (L/D) but the range covered on that equilibrium glide flight will be higher for that value because it is directly proportional to L/D. However, the most important parameters are range and endurance which are directly affected by (L/D) ratio. To achieve minimum stalling speed one has to increase the value of lift coefficient. Due to this, stall speed will also be low for flexible and rigid tip. The same pattern can be seen in negative angle of attack.

The range of propeller airplane is directly proportional to $\mathrm{L} / \mathrm{D}$ in a simplified analysis (Céron-Muñoz et al., 2013; Roskam \& Lan, 1997). For a wing with rigid curved tips, the range of propeller airplane will increase by around $7.8 \%$ and for jet-airplane range is proportional to $\frac{C^{0.5} L}{C_{D}}$ so the increase in range will be around $9 \%$. The climb rate of propeller airplane is directly proportional to $\frac{C^{1.5} L}{C_{D}}$ which predict 
an increase of $13.5 \%$. It can be compared with Céron-Muñoz et al. (2013) who obtained an (L/D) $\max$ of $12 \%$ for multi winglets, and an increase in the range for propeller airplane by $7 \%$.for Jet-airplane it is around $8 \%$ and increase in rate of climb is around $12 \%$. These values are close to the tested wing tips data reported here. From a certain altitude, the glide range will also be higher for greater $(\mathrm{L} / \mathrm{D})_{\max }$. Wings produce major part of airplane lift and drag so any improvement due to wing tips is crucial. Rigid curved tip seems to offer more advantages over flat multi winglets. Similarly, due to decrease in vortex intensity the distance and danger posed to the following airplane can be lessened which ultimately result in increased frequency of airplane landing

\section{Conclusion}

Flexible and rigid wing tips with curved $\&$ flat shapes were tested in the IIUM Low Speed wind tunnel on a flat plate base wing of aspect ratio three. It is observed that wings with rigid curved tips substantially increase the (L/D) ratio by $20 \%$ higher than the base wing. This is better than all other wing tips tested. The increase is noted with five wing tips emulating bird primary feathers in contrast to the previous claims that only up to three wingtips are beneficial for improved performance. An improvement of $7.8 \%$ in the range for propeller engine aircraft and a $9 \%$ increase in range for Jet-airplane aircraft seems to be possible. The long held view that elasticity of bird feather has to do with drag reduction is still true in this experiment with some improvement in aerodynamic coefficients. 


\section{References}

Albertani, R., Stanford, B., Hubner, J. P., \& Ifju, P. G. (2007). Aerodynamic coefficients and deformation measurements on flexible micro air vehicle wings. Experimental Mechanics, 47(5), 625-635. https://doi.org/10.1007/s11340-006-9025-5

Ananda, G. K., Sukumar, P. P., \& Selig, M. S. (2015). Measured aerodynamic characteristics of wings at low Reynolds numbers. Aerospace Science and Technology, 42, 392-406. https://doi.org/10.1016/j.ast.2014.11.016

Aono, H., Chimakurthi, S., Cesnik, C., Liu, H., \& Shyy, W. (1996). Computational Modeling of Spanwise Flexibility Effects on Flapping Wing Aerodynamics. In 47th AIAA Aerospace Sciences Meeting including The New Horizons Forum and Aerospace Exposition. Reston, Virigina: American Institute of Aeronautics and Astronautics. https://doi.org/10.2514/6.20091270

Bachmann, T., Emmerlich, J., Baumgartner, W., Schneider, J. M., \& Wagner, H. (2012). Flexural stiffness of feather shafts: geometry rules over material properties. Journal of Experimental Biology, 215(3), 405-415. https://doi.org/10.1242/jeb.059451

Beechook, a, \& Wang, J. (2013). Aerodynamic Analysis of Variable Cant Angle Winglets for Improved Aircraft Performance. Proceedings of the 19th International Conference on Automation \& Computing, (September), 13-14.

Blick, E. F., Watson, D., Belie, G., \& Chu, H. (1975). Bird Aerodynamic Experiments. In Swimming and Flying in Nature (pp. 939-952). Boston, MA: Springer US. https://doi.org/10.1007/978-1-4757-1326-8_30

Bourdin, P., Gatto, a. ., \& Friswell, M. (2006). The Application of Variable Cant Angle Winglets for Morphing Aircraft Control. 24th Applied Aerodynamics Conference, (June), 1-13.

Cerón-Muñoz, H., Catalano, F., \& Coimbra, R. (2008). Passive, Active, and Adaptive Systems for Wing Vortex Drag Reduction. 26th International Congress of The Aeronautical Sciences, 1-12. Retrieved from http://icasproceedings.net/ICAS2008/PAPERS/256.PDF 
Céron-Muñoz, H. D., Cosin, R., Coimbra, R. F. F., Correa, L. G. N., \& Catalano, F. M. (2013). Experimental Investigation of Wing-Tip Devices on the Reduction of Induced Drag. Journal of Aircraft, 50(2), 441-449. https://doi.org/10.2514/1.C031862

Combes, S. A., \& Daniel, T. L. (2003). Flexural stiffness in insect wings. II. Spatial distribution and dynamic wing bending. The Journal of Experimental Biology, 206(Pt 17), 2989-97. https://doi.org/10.1242/JEB.00524

Cone, C. D. (1962). The Theory of Induced Lift and Minimum Induced Drag of Non-planar Lifting Systems. Nasa Tr R-139.

Cosin, R., C., F.M., C., L.G.N., \& Entz, R. M. . (2010). Aerodynamic Analysis of Multi-Winglets for Low. 27th International Congress of the Aeronautical Sciences, 1-10.

Council, N. R. (2007). Assessment of Wingtip Modifications to Increase the Fuel Efficiency of Air Force Aircraft. DC: The National Academies Press. Retrieved from https://doi.org/10.17226/11839

Eberhardt, S. (2007). US7900876 B2. Retrieved from https://www.google.com/patents/US7900876

Faye, R., Laprete, R., \& Winter, M. (2002). Blended winglets. Aero, Boeing,(17), January. Retrieved from ftp://217.122.167.178/Family/Aviation/Publicaties/Boeing/winglets.pdf

Giuni, M., \& Green, R. B. (2013). Vortex formation on squared and rounded tip. Aerospace Science and Technology, 29(1), 191-199. https://doi.org/10.1016/J.AST.2013.03.004

Gordnier, R. E. (2009). High fidelity computational simulation of a membrane wing airfoil. Journal of Fluids and Structures, 25(5), 897-917. https://doi.org/10.1016/J.JFLUIDSTRUCTS.2009.03.004

Graham, R. . (1932). Safety Devices in Wing Birds. The Journal of the Royal Aeronautical Society, 36(253), 24-58. https://doi.org/10.1017/S0368393100111708 
Lockwood, R., Swaddle, J. P., \& Rayner, J. M. V. (1998). Avian Wingtip Shape Reconsidered: Wingtip Shape Indices and Morphological Adaptations to Migration. Journal of Avian Biology, 29(3), 273. https://doi.org/10.2307/3677110

Macleod, G. D. (1980). Mechanical Properties of Contour Feathers. J. Exp. Biol, $87,65-71$.

Munk, M. (1923). The minimum induced drag of aerofoils. Naca-Tr-121. Retrieved from https://ntrs.nasa.gov/search.jsp?R=19800006779\%5Cnhttp://www.engbrasil. eng.br/index_arquivos/art73.pdf

Nachtigall, W., \& Kempf, B. (1971). Vergleichende Untersuchungen zur flugbiologischen Funktion des Daumenfittichs (Alula spuria) bei Vugeln. Zeitschrift Fur Vergleichende Physiologie, 71(3), 326-341. https://doi.org/10.1007/BF00298144

Norberg, U. M. (2012). Vertebrate flight: mechanics, physiology, morphology, ecology and evolution (Vol 27). Springer Science \& Business Media.

Oehme, H. (1977). On the aerodynamics of separated primaries in the avian wing.Scale effects in animal locomotion. (T. Pedley, Ed.). New York: Academic Press.

Pelletier, A., \& Mueller, T. J. (2000). Low Reynolds Number Aerodynamics of Low-Aspect-Ratio, Thin/Flat/Cambered-Plate Wings. Journal of Aircraft, 37(5), 825-832. https://doi.org/10.2514/2.2676

Pennycuick, C. J., \& Lock, A. (1976). Elastic energy storage in primary feather shafts. Journal of Experimental Biology, 64(3).

Purslow, P. P., \& Vincent, J. F. V. (1978). Mechanical Properties of primary feathers from the pigeon. Journal of Experimental Biology, 72, 251-260.

Raspet.A. (1950). Performance measurements of a soaring bird. OSTIV, 9, 14-17.

Reddig, E. (1978). Der Ausdrucksflug der Bekassine (Capella gallinago gallinago). Journal of Ornithology, 119(4), 357-387. https://doi.org/10.1007/BF01643130 
Rojratsirikul, P., Wang, Z., \& Gursul, I. (2009). Unsteady fluid-structure interactions of membrane airfoils at low Reynolds numbers. Experiments in Fluids, 46(5), 859-872. https://doi.org/10.1007/s00348-009-0623-8

Rojratsirikul, P., Wang, Z., \& Gursul, I. (2010). Unsteady Aerodynamics of Low Aspect Ratio Membrane Wings. In 48th AIAA Aerospace Sciences Meeting Including the New Horizons Forum and Aerospace Exposition. Reston, Virigina: American Institute of Aeronautics and Astronautics. https://doi.org/10.2514/6.2010-729

Rojratsirikula.P, GencabM.S.Z., Wanga, \& I, G. (2011). Flow-induced vibrations of low aspect ratio rectangular membrane wings. Journal of Fluids and Structures, 27(8), 1296-1309. https://doi.org/10.1016/J.JFLUIDSTRUCTS.2011.06.007

Roskam, J., \& Lan, C. E. (Chuan-T. E. (1997). Airplane aerodynamics and performance. Lawrence: DARcorporation.

Sachs, G., \& Moelyadi, M. A. (2006). Effect of slotted wing tips on yawing moment characteristics. Journal of Theoretical Biology, 239(1), 93-100. https://doi.org/10.1016/j.jtbi.2005.07.016

Serdar, G. M. (2013). Unsteady aerodynamics and flow-induced vibrations of a low aspect ratio rectangular membrane wing with excess length. Experimental Thermal and Fluid Science, 44, 749-759. https://doi.org/10.1016/J.EXPTHERMFLUSCI.2012.09.018

Shields, M., \& Mohseni, K. (2012). Effects of sideslip on the aerodynamics of low-aspect-ratio low-reynolds-number wings. AIAA Journal, 50(1), 85-99. https://doi.org/10.2514/1.J051151

Siddiqui, N. A., Asrar, W., \& Sulaeman, E. (2017). Literature Review : Biomimetic and Conventional Aircraft Wing Tips. International Journal of Aviation, Aeronautics, and Aerospace, 4(2). https://doi.org/10.15394/ijaa.2017.1172

Smith, M. J., Komerath, N., Ames, R., \& Wong, O. (2001). Performance analysis of a wing with multiple winglets. Technology, 1-10. 
Smith, R., \& Shyy, W. (1996). Computation of aerodynamic coefficients for a flexible membrane airfoil in turbulent flow: A comparison with classical theory. Retrieved from http://oasc12039.247realmedia.com/RealMedia/ads/click_lx.ads/www.aip.or $\mathrm{g} / \mathrm{pt} / \mathrm{adcenter/pdfcover \_ test/L-37/522021942/x01/AIP-}$ PT/PoF_ArticleDL_051717/PTBG_orange_1640x440.jpg/434f71374e315a5 56e61414141774c75?x. https://doi.org/10.1063/1.869122

Sohn, M. H., \& Chang, J. W. (2012). Visualization and PIV study of wing-tip vortices for three different tip configurations. Aerospace Science and Technology, 16(1), 40-46. https://doi.org/10.1016/j.ast.2011.02.005

Swaddle, J. P., \& Lockwood, R. (2003). Wingtip shape and flight performance in the European starling Sturnus vulgaris. Ibis, 145(3), 457-464. https://doi.org/10.1046/j.1474-919X.2003.00189.x

Trail, P. W. (2014). Identification of bald and golden eagle feathers. Ashland, $\mathrm{OH}$ : Ashland Publications.

Tucker, V. (1993). Gliding birds: reduction of induced drag by wing tip slots between the primary feathers. Journal of Experimental Biology, 180(1), 285310. Retrieved from http://jeb.biologists.org/content/180/1/285.short

Tucker, V. (1995). Drag reduction by wing tip slots in a gliding Harris' hawk, Parabuteo unicinctus. The Journal of Experimental Biology, 198(Pt 3), 77581. Retrieved from http://www.ncbi.nlm.nih.gov/pubmed/9318544

Tucker, V. A. (1987). Gliding Birds: the Effect of Variable Wing Span. Journal of Experimental Biology, 133, 33-58.

Weierman, J. R. (2010). Winglet design and optimization for UAVs. ProQuest Dissertations and Theses, 1481035(July), 108. https://doi.org/10.2514/6.2010-4224

Whitcomb, R. T. (1976). A design approach and selected wind tunnel results at high subsonic speeds for wing-tip mounted winglets. Nasa Tn D-8260, (July), 1-33. Retrieved from http://ntrs.nasa.gov/archive/nasa/casi.ntrs.nasa.gov/19760019075.pdf

Withers, P. C. (1981). An aerodynamic analysis of bird wings as fixed aerofoils. Journal of Experimental Biology, 90, 143-162. 